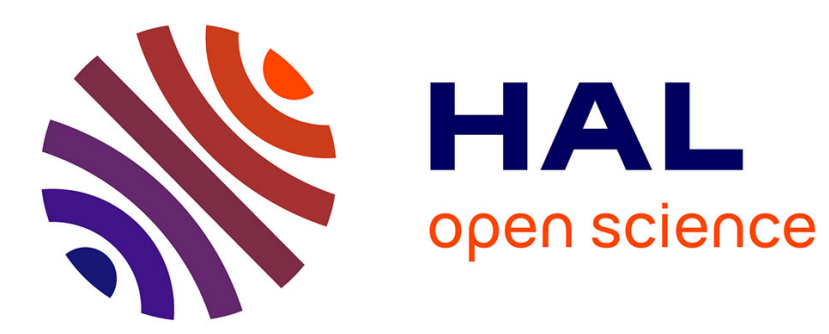

\title{
Thermomechanical behaviour and finite element modelling of metal matrix composites
}

\author{
N. Hansen, D. Juul Jensen, Y.-L. Liu, N. Sørensen
}

\section{To cite this version:}

N. Hansen, D. Juul Jensen, Y.-L. Liu, N. Sørensen. Thermomechanical behaviour and finite element modelling of metal matrix composites. Journal de Physique IV Proceedings, 1993, 03 (C7), pp.C71705-C7-1710. 10.1051/jp4:19937267 . jpa-00251907

\section{HAL Id: jpa-00251907 https://hal.science/jpa-00251907}

Submitted on 1 Jan 1993

HAL is a multi-disciplinary open access archive for the deposit and dissemination of scientific research documents, whether they are published or not. The documents may come from teaching and research institutions in France or abroad, or from public or private research centers.
L'archive ouverte pluridisciplinaire HAL, est destinée au dépôt et à la diffusion de documents scientifiques de niveau recherche, publiés ou non, émanant des établissements d'enseignement et de recherche français ou étrangers, des laboratoires publics ou privés. 


\title{
Thermomechanical behaviour and finite element modelling of metal matrix composites
}

\author{
N. HANSEN, D. JUUL JENSEN, Y.-L. LIU and N.J. SØRENSEN \\ Materials Department, Risø National Laboratory, 399 Frederiksborgvej, 4000 Roskilde, Denmark
}

\begin{abstract}
Experimental observations of the behaviour of aluminium based composites are compared with finite element micromechanical model predictions. The composites are reinforced with whiskers of SiC and the following phenomena are discussed: (i) Dislocation configurations and strain distribution, (ii) Flow stress in tension at room temperature, (iii) Crystallographic texture after cold-rolling and recrystallization.
\end{abstract}

\section{INTRODUCTION}

Improvement in the properties and cost reduction are important issues in the development of metal matrix composites (MMCs). Research is therefore devoted to an optimization of materials and process parameters involving both experimental studies and computer modelling. Discontinuously reinforced aluminium matrix composites are at present of special interest due to their industrial potential $(1,2)$. The reinforcement in such composites can be fibres, platelets, particles and whiskers. In the present study we are only concerned with whiskers.

Commercial aluminium matrix composites have a quite complex chemical composition and microstructure. Experimental materials have therefore been chosen for this investigation in order to facilitate the analysis of experimental data. Such composites have been manufactured by a powder metallurgy route and consist of a relatively low volume fraction of reinforcement $(2-10 \mathrm{vol}$ \% $\mathrm{SiC})$ dispersed in an aluminium matrix. Specimens have been cold deformed in tension and by cold rolling. The cold-rolled specimens have been heat treated in order to follow nucleation and growth. For a series of MMCs the flow stress and the texture have been measured at increasing plastic strain and the microstructure has been characterized using TEM.

In parallel to the experimental work the behaviour of the composites has been predicted using a finite element based micromechanical model. This model calculates the stress and strain distribution near the reinforcement as well as the overall stress-strain behaviour for different volume contents of the reinforcement. Model predictions are throughout the paper related to the experimental observations of dislocation configurations, flow stress and crystallographic texture. 


\section{EXPERIMENTAL}

Aluminium based composites have been manufactured from atomized aluminium powder having an average particle size of about $6 \mu \mathrm{m}$. The oxide from the surface of the particle appears as 0.8 vol., $\%$ aluminium oxide particles in strips of fine platelets (average diameter of $52 \mathrm{~nm}$, thickness of $8.3 \mathrm{~nm}$ ) aligned with the working direction of the composite. The whiskers have been made by the Tokai Carbon Co. Ltd., Japan and are $\beta$-type (cubic) SiC single crystals. In the composite they have a mean diameter of $0.5 \mu \mathrm{m}$ and a mean length of $2.5 \mu \mathrm{m}$. Volume contents of 2,4 and $10 \mathrm{vol} . \% \mathrm{SiC}$ have been used in this study. The composites containing 2 and $4 \% \mathrm{SiC}$ have been examined in the recrystallized state. The composite containing $10 \% \mathrm{SiC}$ could not be recrystallized and has been examined in the hot extruded state. Testing procedures have been described elsewhere $(3-5)$.

The composite behaviour is modelled by a full 3-D elastic-viscoplastic finite element model, using a regular infinite array of parallelpiped aluminium cells as the idealized material model (6). Each cell has a hexagonal-cylindrical short fibre embedded in the center and a perfect bonding is assumed between the matrix and the fibre. The short fibres are all parallel with aligned ends and the cell aspect ratio is equal to the fibre aspect ratio which is taken to be 5. Further details on the micromechanical formulation will be given in a forthcoming paper.

\section{DISLOCATION CONFIGURATIONS AND STRAIN DISTRIBUTION}

The macroscopic effect of the reinforcement during plastic deformation can be an enhanced microstructural evolution compared to single phase materials and a homogenization of the microstructure (3). Local effects are caused directly by the stress which build up at the reinforcement during temperature changes and during straining. This stress can be relaxed, for example by the generation of dislocations at the reinforcement and by dislocation glide (7). The dislocations assemble at the reinforcement in "deformation zones" characterized by a high dislocation density and by relatively high lattice misorientations. In parallel a cell/subgrain structure builds up in the matrix.

Microstructure - undeformed. A relatively high dislocation density has been found in all materials. The distribution of dislocations in the matrix is reasonably homogeneous and there is no evidence of clustering around the $\mathrm{SiC}$ reinforcement. Quantitative dislocation density measurements have not been carried out but qualitative analysis has shown for 2 vol.\% and 4 vol.\% composite that the dislocation density is higher in the latter which also shows evidence of dislocation cell formation (4). These microstructural findings are in general agreement with model predictions reported in the literature $(8,9)$.

Microstructure - tension. In the early stages of deformation extensive generation of dislocations have been observed at the SiC whiskers. A typical microstructure is shown in Fig. 1, to illustrate that the whisker ends are the sites of most dislocation activity. As the strain increases the dislocation activity spreads along and away from the whiskers and at a still higher strain the microstructure becomes more homogeneous with dislocation cells and subgrains forming in the matrix, see Fig. 2.

Microstructure - cold rolling. Material cold-rolled to 50 and $90 \%$ reduction contains subgrains with a fairly inhomogeneous size distribution $(5,10)$. The matrix deformation structure is not affected strongly by the presence of the reinforcement although there is a tendency that large subgrains are present after $90 \%$ reduction. (This may be a consequence of recovery which occur during/after cold-rolling). Deformation zones with large lattice rotations are observed around the reinforcement and the size of such zones are about the diameter of a whisker. The largest lattice rotations have been found near whisker ends and in the vicinity of whisker clusters. Generally deformation zones have not been observed at single whiskers with a diameter less than $0.5 \mu \mathrm{m}$ (10). The magnitude of lattice misorientations is exemplified in Table 1 for a composite containing 2 vol.\% SiC whiskers cold-rolled to $90 \%$ reduction. 


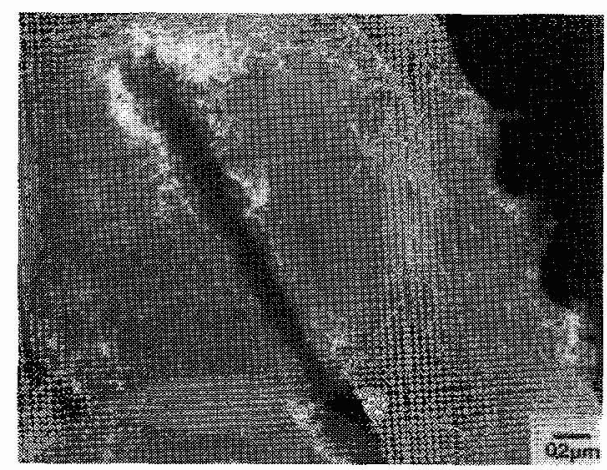

Fig. 1. Recrystallized aluminium composite containing 2 vol.\% SiC whiskers. 5\% tensile strain. Dark field micrograph showing the large dislocation density at a whisker end (4).

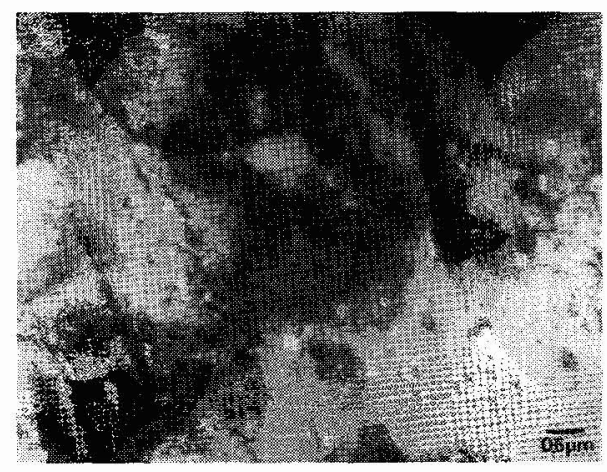

Fig. 2. Same material as in Fig. 1, 9\% tensile strain. Dark field micrograph showing dislocations and subgrains around whiskers (4).

Table I. Lattice Rotations in the Vicinity of Whiskers and Whisker Clusters (10)

\begin{tabular}{||l|c|c|c|}
\hline \multicolumn{2}{|c|}{ SINGLE WHISKER } & \multicolumn{2}{c|}{ CLUSTERS } \\
\hline Rotation Angle $\left(^{\circ}\right)$ & Percentage & Rotation Angle $\left(^{\circ}\right)$ & Percentage \\
\hline 15 & 70 & $>50$ & 75 \\
$10-15$ & 20 & $30-50$ & 10 \\
$5-10$ & 10 & $15-30$ & 15 \\
\hline
\end{tabular}

Micromechanical modelling. The finite element model has been used to calculate the distribution of the von Mises stress and the plastic strain as a function of the applied stress and strain. An example from such calculations is shown in Fig. 3. Fig. 3 shows that the local strain increases much more rapidly than the imposed strain and that large strain concentrations build up in the whisker corners. At increasing plastic strain the plastic flow spreads along the whisker and propagates out from the whisker. These model predictions appear to be in very good agreement with the microstructural observations discussed above and they also agree qualitatively with axisymmetric 2-D numerical simulations carried out previously (11).

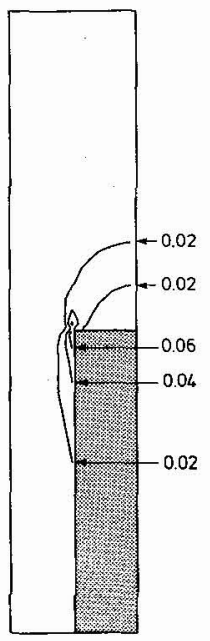

(a)

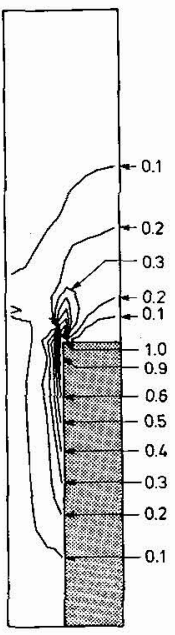

(b)
Fig. 3. Contour plots at a whisker drawn as a function of the imposed tensile strain. (a) and (b) show contours of constant effective plastic strain at the overall strains 0.0067 and 0.061 . 
The strain distribution in discontinuous composites deformed at large strain has not been investigated to the authors' knowledge. However, in a continuous fibre composite deformed $30 \%$ in channel die compression the strain distribution has been investigated using 2-D finite element method calculations (12). This calculations show to be in agreement with optical grid measurements that local strain gradients exist at the fibres but that the regions of highest strain are formed in the matrix between the fibres (12).

\section{FLOW STRESS}

Tension. Fig. 4 shows stress-strain curves for composite containing 2 and 10 vol.\% whiskers. The curves show a large work hardening rate at small strains which increases significantly when the volume concentration of whiskers is increased. The curves also show that the effect of the reinforcement on the flow stress is not so pronounced above 3\% plastic strain. The flow stress behaviour shown in Fig. 4 is in good agreement with the observed microstructural evolution.

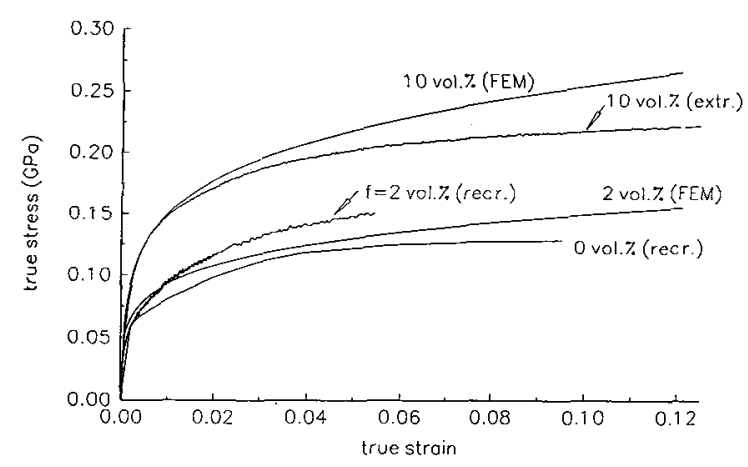

Fig. 4. Experimental and predicted stress-strain curves as a function of the volume concentration of the reinforcement. See text for discussion.

The flow stress contribution caused by dislocations can be estimated on basis of empirical equations where the strength determining parameter is the dislocation density or the cell/subgrain size. Besides dislocation strengthening the Orowan stress and the internal stress contribute to the flow stress. This stress depends on strain and on reinforcement parameters such as aspect ratio, size, volume fraction and distribution (4, 8). Calculations of the flow stress agree qualitatively with the behaviour shown in Fig. 4 and good quantitative agreement has been obtained when calculating the flow stress at a given strain (4).

Micromechanical modelling. FEM calculations of the flow behaviour of composites is based on the constitutive equation of the matrix metal derived from the uniaxial stress-strain curve for the unreinforced material by fitting a power law equation. This type of calculations does not consider dislocation strengthening and internal stresses separately but estimates the total flow stress of the composites which is increased due to constrained plastic flow caused by the presence of the reinforcement. The 3-D model has been applied to predict the stress-strain curves in tension of aluminium composites containing 2 and 10 vol.\% SiC whiskers. As shown in Fig. 4, the model predicts correctly the rapid work hardening rate at small strains and the increase in flow stress with increasing volume concentrations of the reinforcement. The model overpredicts the flow stress in the composite containing 10 vol.\% whiskers. An overprediction has also been found in 2-D modelling (11) but it is shown (13) that the prediction can be improved by allowing the aligned whiskers in a periodic way to overlap partially (clustering).

\section{CRYSTALLOGRAPHIC TEXTURE}

Deformation texture. The presence of the reinforcement affects the flow pattern both in the matrix and 
locally at the reinforcement. Local effect have been studied extensively especially the structural characteristics of deformation zones at the reinforcement present in regular distribution and as clusters $(5$, 8 , 14). Local orientation measurements have also been carried out at the reinforcement and it is generally found that this local texture can be described as a spread rolling/random texture. The volume taken up by the deformation zones is much larger than the volume of the reinforcement and it follows that the deformation texture should weaken with increasing volume fraction of the reinforcement, which is observed (15).

In the present aluminium matrix composites the texture after cold-rolling is of the copper type. The volume concentrations of the various components after $90 \%$ cold-rolling are listed in Table 2 . The concentrations are calculated by integration over $15^{\circ}$ around the respective components in the ODF. Table 2 shows that the total concentrations of rolling texture components are significantly weaker in the composite than in the matrix. Table 2 also shows that the ratios between the individual rolling components are very different in the aluminium and the composite. This indicates that different flow patterns may operate in the two materials.

Table 2. Volume Concentration in Pct. of Main Rolling Texture Component of $90 \%$ Cold-Rolling

\begin{tabular}{||l|c|c|c|c||}
\hline Material & $\begin{array}{c}\{110\} \\
<112>\end{array}$ & $\begin{array}{c}\{123\} \\
<634>\end{array}$ & $\begin{array}{c}\{112\} \\
<111>\end{array}$ & $\begin{array}{c}\text { Sum of } \\
\text { rolling components }\end{array}$ \\
\hline Unreinforced & 13.5 & 36.9 & 23.9 & 74.3 \\
$2 \% \mathrm{SiC}$ & 5.2 & 22.8 & 37.8 & 65.8 \\
\hline
\end{tabular}

Recrystallization texture. The effect of the reinforcement is reflected in the recrystallization texture, which normally is weaker in a composite than in the pure material (15). However, it has been found that a strong texture component can form by recrystallization of a composite (16). This component is a ND rotated cube component $\{100\}<013>$. The component has been termed the $\mathrm{N}$-component and its formation has been explained as follows (16): The large change in lattice orientation observed at whiskers and at whisker clusters (see Table 1) gives rise to a large scatter of crystallographic orientations within the deformation zones. For example may the shear component $\{100\}<011>$ (which is very strong ( 40 vol.\%) in the undeformed composite) be rotated $\sim 25^{\circ}$ around $\mathrm{ND}$ and the $\mathrm{N}$-orientation is formed. By whisker stimulated nucleation, nuclei of $\mathrm{N}$-orientation develop together with nuclei of other (random) orientations and grow out into the matrix. The electron backscattering pattern technique has been used to determine the number and size of $\mathrm{N}$ and other grains (16). It was found that a large number of $\mathrm{N}$ nuclei form, they grow to become significantly larger than grains of other orientations and therefore cause a strong $\mathrm{N}$ recrystallization texture. The relative number and size of the $\mathrm{N}$-grain depends on the annealing temperature (16), and therefore also the strength of the $\mathrm{N}$ recrystallization texture varies significantly with this temperature.

Experimental observations $(5,10)$ and model predictions (12) show that highly strained regions can form in the matrix between the reinforcement when a composite is deformed. Such regions may be sites for nucleation in competition with the deformation zones at the particles, and an effect on the recrystallized texture must be expected. Future experiments and model development should address this problem in general by estimating both strain distribution in the matrix as well as changes in lattice orientation during plastic deformation.

\section{SUMMARY}

For a whisker containing aluminium composite a comparison of the thermomechanical behaviour with 3-D micromechanical model predictions has given the following results: 
(i) Very good agreement is obtained for tensile strained composites between TEM observations of the local dislocation distribution at the reinforcement and model predictions of the local strain distribution.

(ii) Good agreement is obtained between measured and predicted work hardening rates in tension at low strain whereas the absolute level of the flow stress at high strain is predicted with less precision.

(iii) Predictions of the crystallographic texture requires an extension of the micromechanical model to large strains considering also strain induced changes in lattice orientation.

\section{REFERENCES}

[1] Metal Matrix Composites - Processing, Microstructure and Properties, Proc. 12th Ris $\varnothing$ International Symposium on Materials Science, N. Hansen et al. (eds.), Ris $\emptyset$ National Laboratory, 1991, Roskilde, pp. 746.

[2] Clyne, T.W. and Withers, P.J., An Introduction to Metal Matrix Composites, Cambridge University Press 1993, pp. 509.

[3] Hansen, N., Juul Jensen, D. and Liu, Y.L., Mat. Sci. Forum 113-115, (1993) 55.

[4] Barlow, C.Y. and Hansen, N., Acta Metall. Mater. 39 (1991) 1971.

[5] Liu, Y.L., Juul Jensen, D. and Hansen, N., Metal Trans. A, 23A (1992) 807.

[6] Sørensen, N., Needleman, A. and Tvergaard, V., Mat. Sci. Engng. A158 (1992) 129.

[7] Ashby, M.F., Phil. Mag. 21 (1970) 399.

[8] Withers, P.J., Stobbs, W.M. and Pedersen, O.B., Acta Metall. 37 (1989) 3061.

[9] Povirk, G.L., Needleman, A. and Nutt, S.R., Mat. Sci. Engng., A132 (1991), 31.

[10] Liu, Y.L., Hansen, N. and Juul Jensen, D. Metall. Trans. A, 20A (1989) 1743.

[11] Christman, T., Needleman, A. and Suresh, S., Acta Metall. 37 (1989) 3029.

[12] Poole, W.J., Silvetti, S.P., Embury J.D. and Kocks, U.F., Mat. Sci. Forum, 113-115 (1993) 551.

[13] Tvergaard, V., Acta Metall. Mater. 38 (1990) 185.

[14] Humphreys, F.J. in Recrystallization and Grain Growth of Multiphase and Particle Containing Materials, Proc. 1st Ris $\varnothing$ International Symposium on Metallurgy and Materials Science, 1980, N. Hansen et al. (eds.), Ris $\emptyset$ National Laboratory, Roskilde, 1991, 35.

[15] Juul Jensen, D., Hansen, N. and Humphreys, F.J., in Proc. 8th Int. Conf. on Textures of Materials, J.S. Kallend and G. Gottstein (eds.), The Metallurgical Society, Warrendale, PA., 1988, 438.

[16] Juul Jensen, D., Hansen, N. and Liu, Y.L., Mater. Sci. Techn. 7 (1991) 369. 